\title{
PERFIL MICROBIOLÓGICO DO LEITE MATERNO DO BANCO DA MATERNIDADE EVANGELINA ROSA - TERESINA (PIAUÍ)
}

\author{
ANTÔNIO CHAVES DE ASSIS NETO * \\ MARIA MARLUCIA GOMES PEREIRA ** \\ THEONAS GOMES PEREIRA *** \\ MARIA DO CARMO M. SANTOS ***
}

\begin{abstract}
Amostras de leite materno do banco da Maternidade Evangelina Rosa, localizada em Teresina, PI (Brasil) foram avaliadas quanto a qualidade microbiológica. As amostras de leite cru apresentaram média de $5,7 \times 10^{5} \mathrm{UFC} / \mathrm{mL}$ na contagem de aeróbios mesófilos e $6,0 \times 10^{2} \mathrm{UFC} / \mathrm{mL}$ na contagem de psicrotróficos. Oito amostras (32\%) tiveram valores de $10^{5}$ a $>300$ x $10 \mathrm{UFC} / \mathrm{mL}$ para contagem de Staphylococcus aureus. Na enumeração de coliformes totais e fecais os valores obtidos foram de $<0,3 \mathrm{a} \geq 240 \mathrm{NMP} / \mathrm{mL}$. $O$ leite pasteurizado apresentou média de $1,0 \times$ $10^{2} \mathrm{UFC} / \mathrm{mL}$ para contagem de aeróbicos mesófilos. Nenhuma das amostras apresentou coliformes totais, fecais e $S$. aureus. A pasteurização é de vital importância para manutenção da qualidade higiênico-sanitária em bancos de leite humano.
\end{abstract}

\section{INTRODUÇÃO}

O leite materno assume fundamental papel como alimento para o recém nascido. Os bebês alimentados apenas com leite materno encontram-se na fase mais sadia de sua vida, pois este preenche perfeitamente suas demandas de nutrição e de higiene.

O número de crianças em estado de subnutrição e desnutrição no Brasil é considerado bastante elevado, contribuindo significativamente para 0 aumento da taxa de mortalidade infantil.

* Bolsista de iniciação científica, Aluno do Curso de Medicina Veterinária, Centro de Ciências Agrárias, Universidade Federal do Piauí (UFPI), Terezina, PI.

** Professora do Departamento de Morfofisiologia Veterinária, Centro de Ciências Agrárias, UFPI, PI. (e-mail: marlug@ufla.br).

*** Nutricionista do Banco de Leite da Maternidade Evangelina Rosa, Teresina, Piauí. 
Na Índia, 36\% das crianças da área rural e 40\% dos pobres urbanos são alimentados exclusivamente ao peito até idade de 1 ano, e para um quinto destas crianças a desmamentação só começa depois de um ano e meio de idade (UNICEF, 1984).

A composição química do leite humano atende às necessidades nutricionais e as peculiaridades fisiológicas do metabolismo do recém nascido. Até o sétimo dia pós-parto, o produto de secreção láctea da nutriz é o colostro. Este caracteriza-se como líquido espesso de coloração amarelada, com densidade correspondente a $1.050 \mathrm{~g} / \mathrm{cm}^{3}$, coagulável a $72{ }^{\circ} \mathrm{C}$ e dispondo de glóbulos de gordura irregularmente distribuídos. $\mathrm{O}$ colostro é gradativamente substituído pelo leite, líquido branco e opaco com pouco odor, sabor levemente adocicado, com secreção neutra ou levemente alcalina e densidade de $1.030 \mathrm{~g} / \mathrm{cm}^{3}(3)$.

O Ministério da Saúde vem promovendo e desenvolvendo estudos, visando a busca de metodologias alternativas para o controle de qualidade na rotina dos bancos de leite. A implantação do Programa Nacional de Incentivo ao Aleitamento Materno (PNIAM) é de grande importância para a retomada da valorização do fornecimento do mesmo, no entanto, este programa tem gerado discussões sob o ponto de vista da saúde pública (3).

O Banco de Leite Humano (BLH) é responsável pela promoção e incentivo ao aleitamento materno, bem como pela execução de atividades de coleta, processamento e controle de qualidade de colostro, leite de transição e humano maduro. A posterior distribuição do leite humano ocorre sob prescrição de médicos ou nutricionistas, obrigatoriamente vinculados a um Hospital Materno e/ou Infantil. Trata-se de centro especializado, sem fins lucrativos, sendo vetada a comercialização dos produtos distribuídos (3).

As normas para implantação e funcionamento de Bancos de Leite Humano, elaborados pelo INSTITUTO NACIONAL DE ALIMENTAÇÃO E NUTRIÇÃO (INAN), dispõem sobre a pasteurização do leite materno e asseguram a obrigatoriedade deste procedimento, uma vez que o leite materno não é estéril. A coleta deve ser realizada com cuidados de assepsia para que não haja contaminação do leite com microrganismos presentes nas porções mais externas da mama ou do ambiente.

Os microrganismos presentes no leite humano podem ser classificados segundo a sua origem, como contaminantes primários e secundários. A flora ou microbiota de contaminação primária envolve microrganismos que passam diretamente da corrente sangüínea para o leite, como o HIV, enquanto que os contaminantes secundários são originários da flora normal da pele. A microbiota do leite humano pode ser ainda classificada, quanto a sua patogenicidade, em normal ou saprófita e patogênica (12). 
A pasteurização não é totalmente eficaz, pois experimentos realizados por ALMEIDA (2) demonstraram que o tratamento térmico do leite humano, em banho-maria, apresenta redução de 55,8\% para mesófilos; 44,72\% para bolores e leveduras; $67,8 \%$ para psicotróficos e de $57,9 \%$ a $100 \%$ para estafilococos.

Mesmo inativando alguns fatores nutricionais e protetores contidos no colostro do leite, o método de pasteurização é necessário já que não se pode garantir que a coleta tenha ocorrido em condições higiênico sanitárias adequadas. É mais seguro distribuir produto com níveis nutricionais e protetores menores do que produto com microrganismos que podem oferecer sérios riscos (12).

O processo de pasteurização recomendado pela legislação brasileira consiste em utilizar banho-maria regulado, de forma que a temperatura do mesmo seja suficiente para aquecer o leite a $62,5^{\circ} \mathrm{C}$. Após o préaquecimento deve-se marcar 30 minutos e resfriar o leite, imediatamente, por imersão em água e gelo, $\pm 5^{\circ} \mathrm{C}(3)$.

A introdução da embalagem e a manipulação do produto envolve os contaminantes secundários, advindos do meio ambiente. Isto torna preocupante a qualidade sanitária do produto, o que não acontece quando se trata de amamentação direta. Mesmo dispondo de uma série de substâncias protetoras em sua composição, o leite materno não pode ser encarado como absolutamente seguro (12). Em 78 amostras de leite humano, congeladas e analisadas após 24 horas foram observados na contagem total (colônias $/ \mathrm{mL}$ ) valores $<100$ para 5 amostras, $100-1000$ para 9, $1000-10.000$ para $12,10.000-100.000$ para 22 e $>100.000$ para 30 amostras. Os mesmos autores citam que, dentre as espécies de microrganismos isolados em 110 amostras as mais freqüentes foram Staphylococcus epidermidis (23,7\%), Staphylococus aureus (14,6\%), $\gamma$-streptococci (16,2\%) e Alcaligenes faecalis (14,6\%) (14).

O número desejável de microrganismos em contagem total é de 2.000 células $/ \mathrm{mL}$, podendo atingir o índice máximo tolerável de 10.000 células por mililitro. Isto quando associados à ausência de patógenos, tais como os pertencentes aos grupos coliformes, estafilococos e salmonelas (8).

De acordo com experimento realizado por EYRES et al. (5), a contagem inicial de Staphylococcus aureus de $2,8 \times 10^{7} \mathrm{UFC} / \mathrm{mL}$ foi totalmente destruída após pasteurização a $62,5^{\circ} \mathrm{C}$ por 30 minutos.

Estudos realizados por ALMEIDA (2) com leite humano, recém coletado, evidenciaram contagem de até $10^{7} \mathrm{UFC} / \mathrm{mL}$ para mesófilos, $10^{3} \mathrm{UFC} / \mathrm{mL}$ para coliformes, $10^{4} \mathrm{UFC} / \mathrm{mL}$ para estafilococos e $10^{6} \mathrm{UFC} / \mathrm{mL}$ para psicotróficos. No leite pasteurizado, seguido de resfriamento rápido, 
encontrou as seguintes médias: 3,05 UFC/mL para mesófilos, 0,98 UFC/mL, para psicotróficos e ausência por $\mathrm{mL}$ para estafilococos.

Avaliando a qualidade higiênica do leite humano pasteurizado em banco de leite, OLIVEIRA et al. observaram ausência de coliformes em 100\% das amostras e de $10^{\circ}$ a $10^{3} \mathrm{UFC} / \mathrm{mL}$ para contagem padrão em placas, referente a $0,2 \%$ das amostras analisadas (11).

Em trabalho efetuado por DHAR et al., o leite materno foi inoculado com Escherichia coli $\left(10^{6} \mathrm{UFC} / \mathrm{mL}\right)$ e Staphylococcus aureus $\left(10^{7} \mathrm{UFC} / \mathrm{mL}\right)$, sendo submetido a tratamento térmico a $71^{\circ} \mathrm{C}$ em volumes de $5,9,12,3 \mathrm{e}$ $18,9 \mathrm{~mL} / \mathrm{min}$. Ao término do processo verificaram completa inativação de ambos os microrganismos (4).

Avaliando a destruição térmica de Escherichia coli e Klebsiella pneumoniae em leite materno (9), MORGAN et al. determinaram os valores de $D$ e $Z$ para estes microrganismos. $O$ valor de $D$ para $E$. coli a $60{ }^{\circ} \mathrm{C}$ foi $31,5 \mathrm{~s}$ e para $K$. pneumoniae a $60^{\circ} \mathrm{C}$ foi $1,3 \mathrm{~s}$. $O$ valor de $Z$ para $E$. coli foi $3,2^{\circ} \mathrm{C}$ e para K. pneumoniae foi $2,8^{\circ} \mathrm{C}$.

O perfil bacteriológico do leite humano de doadoras individuais e de um pool de amostras de banco de leite comercial foi analisado (7). Todas as amostras mostraram-se negativas para coliformes e na contagem total de aeróbios os valores variaram de $<1,0$ a 5,5 × $10^{3} \mathrm{UFC} / \mathrm{mL}$, com média de $1,5 \times 10^{3} \mathrm{UFC} / \mathrm{mL}$. No pool de amostras a contagem de coliformes alcançou valores de $<1,0$ a $3,4 \times 10^{5} \mathrm{UFC} / \mathrm{mL}$, tendo como média $6,8 \times 10^{4} \mathrm{UFC} / \mathrm{mL}$. A contagem total de aeróbios foi $2,7 \times 10^{3}$ a $1,4 \times 10^{6} \mathrm{UFC} / \mathrm{mL}$ com média de $2,9 \times 10^{5} \mathrm{UFC} / \mathrm{mL}$. Os microrganismos isolados das doadoras individuais foram identificados como Staphylococcus, sendo $82 \%$ de $S$. epidermidis e $10 \% S$. hominis e $S$. aureus, além de outras espécies detectadas em apenas $1 \%$ das amostras. Dos organismos isolados do pool de amostras, 39\% eram S. epidermidis, 11\% Klebsiella pneumoniae, $11 \%$ Citrobacter spp, 7\% Serratia liquefaciens, 5\% Gram negativos não identificados e 3\% Pseudomonas paucimobilis.

Mediante tratamento térmico do leite materno, MUSGROVE et al. (10) observaram redução no número de microrganismos viáveis, bem como mudança do tipo de microrganismo. No leite pasteurizado foram detectadas bactérias não patogênicas, comuns a pele, mas o leite "in natura" apresentou Pseudomonas e outras bactérias Gram negativas, incluindo bactérias potencialmente patogênicas.

O presente trabalho teve como objetivo avaliar a qualidade do leite materno do banco de leite da Maternidade Evangelina Rosa, localizada em Teresina (Piauí). 


\section{MATERIAL E MÉTODOS}

\subsection{MATERIAL}

Leite materno do Banco de leite da Maternidade Evangelina Rosa, Teresina, PI.

\subsection{COLETA DAS AMOSTRAS}

Foram analisadas 40 amostras de leite, sendo 25 de leite "in natura" e 15 de leite pasteurizado. As amostras de $10 \mathrm{~mL}$ cada foram coletadas em tubos de ensaio esterilizados, acondicionadas em caixa de isopor com gelo e encaminhadas ao laboratório de Microbiologia do Núcleo de Estudos, Pesquisas e Processamento de Alimentos (NUEPPA), do Centro de Ciências Agrárias, da Universidade Federal do Piauí (UFPI).

\subsection{ANÁLISES MICROBIOLÓGICAS}

As análises microbiológicas foram realizadas de acordo com métodos do ICMSF (6).

\subsubsection{Determinação do número mais provável de coliformes totais e coliformes fecais (NMP/mL)}

Usando-se a técnica dos tubos múltiplos transferiu-se, assepticamente, $1 \mathrm{~mL}$ das diluições $10^{\circ}, 10^{-1}$ e $10^{-2}$ de amostra, previamente homogeneizada, para uma série de 3 tubos, contendo $10 \mathrm{~mL}$ de caldo verde brilhante bile a $2 \%$ (CVBB) e tubinhos de Durhan invertidos, os quais foram incubados a $35{ }^{\circ} \mathrm{C}$ por $24-48$ horas. Os tubos positivos foram considerados confirmativos para coliformes totais. Para a confirmação de coliformes fecais os tubos foram repicados em caldo EC, com incubação a $44,5^{\circ} \mathrm{C}$, durante $24-48$ horas, sendo considerados positivos os tubos que apresentaram turvação e produção de gás nos tubinhos de Durhan. A determinação do número mais provável de coliformes totais e fecais foi realizada mediante Tabela de Hoskins e os resultados expressos em $\mathrm{NMP} / \mathrm{mL}$.

\subsubsection{Contagem total de aeróbios mesófilos e psicrotróficos}

Utilizou-se a técnica de plaqueamento para contagem padrão de bactérias, sendo inoculados $1 \mathrm{~mL}$ das diluições $10^{-1}$ e $10^{-2} \mathrm{em}$ placas de Petri (duplicata) esterilizadas. Adicionou-se em cada placa, $15 \mathrm{~mL}$ de Ágar Padrão para Contagem (PCA) e após solidificação do ágar, as placas foram incubadas invertidas em estufa a $35 \pm 1^{\circ} \mathrm{C}$, por 48 horas (mesófilas) e a $7 \pm 1 \stackrel{\circ}{ } \mathrm{C}$ (psicrotróficas) por 7 dias. Os resultados foram expressos em unidade formadora de colônia por $\mathrm{mL}(\mathrm{UFC} / \mathrm{mL})$. 


\subsubsection{Contagem de Staphylococcus sp}

A técnica de plaqueamento também foi utilizada para a contagem de Staphylococcus sp, sendo inoculados $0,1 \mathrm{~mL}$ das diluições $10^{-1}$ e $10^{-2}$ na superfície de placas de Petri (duplicata), contendo Ágar Baird Parker. Em seguida, cada porção foi dispersa na superfície com o auxílio de alça de Drigasky e as placas incubadas invertidas em estufa a $35 \pm 1^{\circ} \mathrm{C}$ por 48 horas. As colônias características de Staphylococcus foram inoculadas em $5 \mathrm{~mL}$ de caldo cérebro coração, incubadas a $37{ }^{\circ} \mathrm{C}$ por 24 horas e submetidas as provas de catalase e coloração de Gram. As colônias catalase positiva e cocos Gram + foram consideradas Staphylococcus sp e os resultados expressos em UFC/mL.

\section{RESULTADOS E DISCUSSÃO}

Os resultados das análises microbiológicas do leite "in natura" (Tabela 1) revelaram a ocorrência de contagem para mesófilos variando de $<10^{3}$ a 9,1 $\times 10^{6} \mathrm{UFC} / \mathrm{mL}$ e média de $5,7 \times 10^{5} \mathrm{UFC} / \mathrm{mL}$.

Estudando as características microbiológicas do leite humano recém coletado, com o objetivo de assegurar a constância de todos os fatores ambientais capazes de influenciar a qualidade microbiológica do leite, ALMEIDA (2) conduziu a retirada de amostras em sala de coleta, no próprio Banco de leite. Comparando-se os resultados obtidos para o leite "in natura" com os dados do referido autor verificou-se que, os valores encontrados para mesófilos foram inferiores, apesar da coleta ser realizada não apenas na maternidade, mas também externamente. Já os resultados encontrados por LIN et al. (7) apresentaram valores superiores.

A contagem de psicrotróficos (Tabela 1) no leite "in natura" apresentou média de $6 \times 10^{2} \mathrm{UFC} / \mathrm{mL}$, mostrando-se inferior a obtida por ALMEIDA (2) $\left(10^{6} \mathrm{UFC} / \mathrm{mL}\right)$. Os microrganismos psicrotróficos são capazes de crescer em temperatura menor ou igual a $7 \stackrel{\circ}{\circ}$, independentemente do ponto ótimo de crescimento. Para ocasionarem alterações no leite estas bactérias devem apresentar contagens superiores a $10^{6} \mathrm{UFC} / \mathrm{mL}$. $O$ aspecto importante a ser observado é a produção de enzimas proteolíticas e lipolíticas extracelulares, as quais apresentam considerável resistência térmica, podendo ocasionar problemas mesmo na ausência dos microrganismos produtores (1).

Do total de amostras de leite "in natura" analisadas, 32\% apresentaram contagem de Staphylococcus sp com valores que variaram de $10^{5} \mathrm{UFC} / \mathrm{mL}$ a incontável (diluição $10^{2}$ ). Os valores encontrados por ALMEIDA (2) evidenciaram média de $10^{4} \mathrm{UFC} / \mathrm{mL}$. LIN et al. (1988), isolando microrganismos em doadoras individuais, constataram que $82 \%$ das bactérias isoladas pertenciam ao gênero Staphylococcus sp. 
TABELA 1 - CONTAGEM TOTAL DE AERÓBIOS MESÓFILOS E PSICROTRÓFICOS, NÚMERO MAIS PROVÁVEL DE COLIFORMES TOTAIS E FECAIS E CONTAGEM DE Staphylococcus sp EM LEITE HUMANO "IN NATURA"

\begin{tabular}{|c|c|c|c|c|c|}
\hline Amostras & $\begin{array}{l}\text { Contagem total } \\
\text { de aeróbios } \\
\text { mesófilos } \\
\text { (UFC/mL) }\end{array}$ & $\begin{array}{c}\text { Contagem } \\
\text { total de } \\
\text { aeróbios } \\
\text { psicrotróficos } \\
\text { (UFC/mL) }\end{array}$ & $\begin{array}{l}\text { Staphylococcus sp } \\
\text { (UFC/mL) }\end{array}$ & $\begin{array}{l}\text { Coliformes } \\
\text { totais } \\
(\mathrm{NMP} / \mathrm{mL})\end{array}$ & $\begin{array}{c}\text { Coliformes } \\
\text { fecais } \\
(\mathrm{NMP} / \mathrm{mL})\end{array}$ \\
\hline 1 & $2,9 \times 10^{6}$ & $<10$ & $10^{5}$ & $\geq 240,0$ & $\geq 240,0$ \\
\hline 2 & $3,5 \times 10^{4}$ & $<10$ & $<10$ & $<0,3$ & $<0,3$ \\
\hline 3 & $9,1 \times 10^{6}$ & $<10$ & $>300 \times 10$ & $\geq 240,0$ & $\geq 240,0$ \\
\hline 4 & $1,5 \times 10^{4}$ & $<10$ & $<10$ & $\geq 240,0$ & $\geq 240,0$ \\
\hline 5 & $1,5 \times 10^{4}$ & $<10$ & $6 \times 10^{4}$ & $<0,3$ & $<0,3$ \\
\hline 6 & $8,8 \times 10^{5}$ & $<10$ & $<10$ & 24,0 & $<0,3$ \\
\hline 7 & $3,5 \times 10^{4}$ & $<10$ & $<10$ & 0,4 & $<0,3$ \\
\hline 8 & $1,3 \times 10^{4}$ & $<10$ & $>300 \times 10$ & 4,3 & 1,1 \\
\hline 9 & $1,9 \times 10^{4}$ & $<10$ & $<10^{2}$ & 9,3 & 2,3 \\
\hline 10 & $1,7 \times 10^{4}$ & $<10$ & $<10^{2}$ & 1,5 & 0,7 \\
\hline 11 & $7,5 \times 10^{3}$ & $<10$ & $<10^{2}$ & 24,0 & 24,0 \\
\hline 12 & $5,5 \times 10^{4}$ & $<10$ & $<10^{2}$ & $<0,3$ & $<0,3$ \\
\hline 13 & $1,7 \times 10^{5}$ & $<10$ & $<10^{2}$ & 9,3 & $<0,3$ \\
\hline 14 & $2,6 \times 10^{4}$ & $<10$ & $<10^{2}$ & $<0,3$ & $<0,3$ \\
\hline 15 & $1,8 \times 10^{5}$ & $<10$ & $<10^{2}$ & $<0,3$ & $<0,3$ \\
\hline 16 & $1,4 \times 10^{5}$ & 70 & $<10^{2}$ & $\geq 240,0$ & $<0,3$ \\
\hline 17 & $7,5 \times 10^{3}$ & $<10$ & $<10^{2}$ & 0,9 & $<0,3$ \\
\hline 18 & $2,6 \times 10^{4}$ & $1,5 \times 10^{4}$ & $<10^{2}$ & $\geq 240,0$ & 21,0 \\
\hline 19 & $<10^{3}$ & $<10$ & $<10^{2}$ & $<0,3$ & $<0,3$ \\
\hline 20 & $5,5 \times 10^{4}$ & $<10$ & $2,1 \times 10^{4}$ & 4,3 & $<0,3$ \\
\hline 21 & $4,5 \times 10^{5}$ & $<10$ & $>300 \times 10$ & $\geq 240,0$ & $\geq 240,0$ \\
\hline 22 & $2,6 \times 10^{4}$ & $<10$ & $<10^{2}$ & 46 & 46 \\
\hline 23 & $1,6 \times 10^{4}$ & $<10$ & $2,5 \times 10^{4}$ & 24 & 24 \\
\hline 24 & $1,1 \times 10^{5}$ & $<10$ & $<10^{2}$ & $\geq 240,0$ & 140,0 \\
\hline 25 & $7,7 \times 10^{4}$ & $<10$ & $2,5 \times 10^{4}$ & 46 & 24,0 \\
\hline
\end{tabular}

Os resultados da enumeração de coliformes totais e fecais (Tabela 1) variaram de $<0,3 \mathrm{a} \geq 240 \mathrm{NMP} / \mathrm{mL}$, enquanto que ALMEIDA (1986) obteve média de $10^{3} \mathrm{UFC} / \mathrm{mL}$. LIN et al. (1988) constataram ausência de coliformes em doadoras individuais e no pool de amostras valores que variaram de $<1,0$ a $3,4 \times 10^{5} \mathrm{UFC} / \mathrm{mL}$.

Os resultados das amostras de leite humano pasteurizado (Tabela 2) para mesófilos alcançaram média de $1,1 \times 10^{2} \mathrm{UFC} / \mathrm{mL}$, com valores que variaram de $<10^{-1}$ a $1,2 \times 10^{3} \mathrm{UFC} / \mathrm{mL}$. Os valores obtidos por OLIVEIRA et al. (11) variaram de 1 a $10^{3} \mathrm{UFC} / \mathrm{mL}$ e ALMEIDA (1986) obteve média de $3,05 \mathrm{UFC} / \mathrm{mL}$. 


\section{TABELA 2 - CONTAGEM TOTAL DE AERÓBIOS MESÓFILOS E PSICROTRÓFICOS, NÚMERO MAIS PROVÁVEL DE COLIFORMES TOTAIS E FECAIS E CONTAGEM DE Staphylococcus sp EM LEITE HUMANO PASTEURIZADO}

\begin{tabular}{ccccc}
\hline Amostras & $\begin{array}{c}\text { Contagem total } \\
\text { de aeróbios } \\
\text { mesófilos } \\
\text { (UFC/mL) }\end{array}$ & $\begin{array}{c}\text { Staphylococcus sp } \\
(\text { UFC/mL) }\end{array}$ & $\begin{array}{c}\text { Coliformes } \\
\text { totais } \\
(\mathrm{NMP} / \mathrm{mL})\end{array}$ & $\begin{array}{c}\text { Coliformes } \\
\text { fecais } \\
(\mathrm{NMP} / \mathrm{mL})\end{array}$ \\
\hline 1 & 50 & $<10$ & $<0,3$ & $<0,3$ \\
2 & 10 & $<10$ & $<0,3$ & $<0,3$ \\
3 & 15 & $<10$ & $<0,3$ & $<0,3$ \\
4 & 35 & $<10$ & $<0,3$ & $<0,3$ \\
5 & 210 & $<10$ & $<0,3$ & $<0,3$ \\
6 & $<10$ & $<10$ & $<0,3$ & $<0,3$ \\
7 & 25 & $<10$ & $<0,3$ & $<0,3$ \\
8 & 30 & $<10$ & $<0,3$ & $<0,3$ \\
9 & $<10$ & $<10$ & $<0,3$ & $<0,3$ \\
10 & 15 & $<10$ & $<0,3$ & $<0,3$ \\
11 & 70 & $<10$ & $<0,3$ & $<0,3$ \\
12 & $<10$ & $<10$ & $<0,3$ & $<0,3$ \\
13 & 15 & $<10$ & $<0,3$ & $<0,3$ \\
14 & $<10$ & $<0,3$ & $<0,3$ \\
15 & 1200 & & &
\end{tabular}

Não foi constatada presença de Staphylococcus sp, coliformes totais e fecais no leite pasteurizado, resultados semelhantes aos obtidos por ALMEIDA (2) e OLIVEIRA (11).

EYRES et al. (1978) a partir de contagem inicial de Staphylococcus de $2,8 \times 10^{7} \mathrm{UFC} / \mathrm{mL}$ conseguiram total inativação após a pasteurização. Resultados idênticos foram encontrados por DHAR et al. (4), os quais inocularam E. coli $\left(10^{6} \mathrm{UFC} / \mathrm{mL}\right)$ e $S$. aureus $\left(10^{7} \mathrm{UFC} / \mathrm{mL}\right)$ no leite.

Comparando os dados do leite "in natura" com os do leite pasteurizado verifica-se a importância vital da pasteurização, mesmo com diminuição de nutrientes.

\section{CONCLUSÃo}

De acordo com os resultados do presente estudo pode-se concluir que: 
- o leite humano "in natura" apresentou elevado índice de contaminação, o que pode representar risco à saúde;

- o leite humano após a pasteurização apresentou índice de contaminação bastante reduzido, com média de mesófilos de $1,1 \times 10^{2} \mathrm{UFC} / \mathrm{mL}$ e ausência de coliformes totais e fecais e de Staphylococcus sp;

- o leite materno pasteurizado apresentou condições higiênico-sanitárias satisfatórias e mesmo ocorrendo diminuição de nutrientes, o processo representa papel vital na qualidade higiênico-sanitária do leite materno;

- a coleta assume grande importância na qualidade higiênico-sanitária do leite, tendo em vista que não se pode exercer controle absoluto desta, principalmente na coleta externa.

\begin{abstract}
Maternal milk samples of "Maternidade Evangelina Rosa" bank, located in Teresina, PI (Brazil), were evaluated for its microbiological quality. It was observed that raw milk samples displayed average counts of mesophilic aerobic of $5,7 \times 10^{5} \mathrm{CFU} / \mathrm{mL}$ and psicotrophics counts of $6,0 \times 10^{2} \mathrm{CFU} / \mathrm{mL}$. Eight samples (32\%) presented Staphylococcus aureus counts that varied from $10^{5}$ to $>300 \times 10^{-1} \mathrm{CFU} / \mathrm{mL}$. In total and fecal coliforms enumeration the values obtained varied from 0,3 to $\geq 24 \mathrm{NMP} / \mathrm{mL}$. Pasteurized human milk presented mesophilic aerobic average count of $1,1 \times 10^{2} \mathrm{CFU} / \mathrm{mL}$. None of the analyzed samples presented total, fecal coliforms and $S$. aureus. The pasteurization is of high importance to maintain the hygienic-sanitary quality of human milk bank.
\end{abstract}

\title{
REFERÊNCIAS
}

1 ALMEIDA, A. A. P.; FURTADO Fo, J. Microrganismos psicrotróficos em leite. R. Inst. Latic. Cândido Tostes, Juiz de Fora, v. 48, n. 287, p. 36-40, 1993.

2 ALMEIDA, J. A. G. Qualidade do leite humano coletado e processado em banco de leite. Viçosa, 1986. 68 p. Dissertação (Mestrado), Universidade Federal de Viçosa.

3 BRASIL. Ministério da Saúde. Recomendações técnicas para o funcionamento do banco de leite humano. 2. ed. Brasília, 1993.

4 DHAR, J. et al. Pasteurization efficiency of HTST system for human milk. Journal of Food Science, v. 61, n. 3, p. 569-572, 1996.

5 EYRES, R., ELLIOTT, R. B., HOWLE, R. N., FARMER, K. Low temperature pasteurization of human milk. Med. J. New Zeal., v. 87, p. $134-135,1978$. 
6 ICMSF. Microorganismos de los alimentos: técnicas de análises microbiológicas. Zaragoza: Acribia, 1983. v. 1.

7 LIN, J. F. et al. Bacteriological profiles of human milk from individual donors and pooled samples from a commercial milk bank. Journal Food Protection, v. 51, n. 6, p. 467-470, 1988.

8 LORENZO, J. Alimentos que pueden consumir los ninõs. Arch. Pediat, Uruguay, v. 51, n. 4, p. 282-4, 1980.

9 MORGAN, J. N. et al. Thermal destruction of Escherichia coli and Klebsiella pneumoniae in human milk. Journal of Food Protection, v. 51, n. 2, p. 132-136, 1988.

10 MUSGROVE, M. T. et al. Microbiological examination of pasteurized, deaeratede human milk. Journal Food Protection, v. 52, n. 8, p. 552559, 1989.

11 OLIVEIRA, J. S. et al. Qualidade microbiológica do leite. Revista Instituto de Lacticínios Cândido Tostes, n. 31, p. 15-20, 1976.

12 PASCHOA, M. F. Banco de leite humano: fluxograma e "Lay-out". R. Higiene Alimentar, São Paulo, v. 11, n. 50, p. 18-22, 1997.

13 UNICEF. Importância do leite materno na infância. R. Higiene Alimentar, São Paulo, v. 3, n.3/4, p.172-173, 1984.

14 VAVRA, L.; CHYLKOVÁ, V. Conservation of human milk. Dairy Science, Abstracts, v. 44, n. 12, p. 943, 1982. 